\title{
Bacterial Influence on Textile Wastewater Decolorization
}

\author{
Aamr Alalewi, Cuiling Jiang \\ ${ }^{1}$ Department of Hydrology and Water Resources, Hohai University, Nanjing, China; ${ }^{2}$ State Key Laboratory of Hydrology-Water \\ Resources and Hydraulic Engineering, Hohai University, Nanjing, China. \\ Email: aamralewi@hotmail.com
}

Received May $12^{\text {th }}, 2012$; revised June $15^{\text {th }}, 2012$; accepted July $17^{\text {th }}, 2012$

\begin{abstract}
The study aims to isolate and optimize bacterial strains having the ability to degrade and decolorize azo dyes produced in the final effluent of textile dying industries. In this regard, ten bacterial strains were isolated from wastewater treatment plants, and most of them were subjected to the colored effluents resulting from dilapidated houses. The ability of these bacterial isolations to use a wide range of azo dyes to determine the sole carbon source was determined. According to these screening testes, two bacterial isolations were selected as the most potent decolorizer for azo dyes, and they were identified as Comamanas acidovorns-TN1 and Burkholdera cepace-TN5. The optimization process started with the addition of $1 \mathrm{~g} / \mathrm{l}$ yeast extract, where the decolorization ability of the two strains increased sharply and according to this experiment, the two azo dyes, Acid orange 7 and Direct blue 75, were selected to complete the study. The effect of different conditional and chemical factors on the decolorization process of Acid orange 7 and Direct blue 75 by Comamanas acidovorns-TN1 and Burkholdera cepace-TN5 was studied. Factors that contributed to the difference were different $\mathrm{pH}$, temperature, incubation period, inoculum size, carbon source, nitrogen source and the respective concentrations of yeast extract. This study recommends the application of the two most potent bacterial strains in the decolorization of the azo dyes, along with acid orange 7 and direct blue 75 , specifically in the industrial effluents under all nutritional and environmental conditions.
\end{abstract}

Keywords: Decolorization; Biodegradation; Azo Dys; Textile Wastewater

\section{Introduction}

Environmental pollution has been identified as a major problem in the modern world. The increasing demand for drinkable water, and its dwindling supply, has made the treatment and reuse of industrial effluents an attractive option. One of the most important environmental pollution problems is the color in water courses; although some of these colors are normally present and of "natural" origins (e.g. the color originates from the activity of microorganisms in ponds), a considerable proportion, especially in the lower reaches of rivers that drain large industrial conurbations, originates from industrial effluents. Some colored effluents are associated with the production and use of dyes.

Azo dyes, the largest chemical class of dyes with the greatest variety of colors, have been used extensively for textile, dyeing, and paper painting [1]. These dyes cannot be easily degraded, and some are toxic to higher animals. Over $7 \times 10^{5}$ metric tones of synthetic dyes are produced worldwide every year for dyeing and printing, and out of this, about $5 \%-10 \%$ are discharged with wastewater. The amount of dye lost depends on the class of dye applied; it varies from $2 \%$ loss with the use of basic dyes to about $50 \%$ loss in certain reactive sulfonated dyes [2]. The presence of dyes in aqueous ecosystem diminishes photosynthesis by impeding light penetration into deeper layers thereby deteriorating water quality and lowering the gas solubility. Furthermore, the dyes and/or their degraded by-products may be toxic to flora and fauna [3]. Azo dyes consist of a diazotized amine coupled with an amine or phenol, and contain one or more azo linkages. At least 300 different varieties of azo dyes are extensively used in the textile, paper, food, cosmetics and pharmaceutical industries. The effects of $\mathrm{pH}$, temperature, type and concentration of respiration substrates, and oxygen tension on the rate of biological reduction of a variety of azo dyes have previously been investigated [4, 5]. Several combinations of treatment methods have been developed so far in order to effectively process cottontextile wastewater, with decolorization among the main goals for these processes. Chemical coagulation/flocculation techniques, usually combined with activated sludge treatment, have been among the most common processing methods mainly due to the ease of their application. However, the above methods require high amounts of raw materials (coagulants) and also yield large amount of 
waste solids, leading to the elevation of the total treatment cost. Advanced oxidation processes (Ozonation, $\mathrm{UV} / \mathrm{H}_{2} \mathrm{O}_{2}$ ) are based on the generation of hydroxyl radicals, which are mainly highly reactive oxidants. They are environmental friendly techniques, since no solid wastes are produced. However, they are not cost effective due to the high consumption of both energy and raw material (e.g. hydrogen peroxide). Active carbon adsorption and nanofiltration techniques are able to remove dyes from wastewater. Although, the main disadvantage of these methods is the production of a secondary waste stream (or waste solid) that requires further treatment or disposal.

The anaerobic reduction of azo dyes to simpler compounds has been well researched [6-8]. These and other studies have all demonstrated the ability of anaerobic microbes and sludge to effectively reduce azo dyes to their intermediate structures, thus destroying the apparent color. Many of these intermediates are aromatic amines with constituent side groups. By reducing the dye compounds to their intermediates, the problem of aesthetic pollution is accounted for, but a larger and more deleterious problem may be created. Most azo dyes are nontoxic, but a high percentage of their intermediates have been identified as carcinogens. Because of the toxic potential of many aromatic amines, further degradation of the dye compound is necessary if toxicity is to be eliminated or reduced $[9,10]$. In light of the presumptive evidence, this investigation was designated to fulfill the following objectives:

1) Investigate the potential of bacterial isolations from textile industries wastewater and drains (textile effluent adapted bacteria) in some azo dye biodegradation;

2) Analyze the bioremediation of secondary metabolites of azo dye degradation (secondary aromatic amines) to environmental friendly non toxic form;

3) How to use cost-effective raw materials (as agricultural and industrial wastes) in the dye biodegradation process.

\section{Methodology}

\subsection{Isolation and Cultivation of the Most Efficient Decolorizing Bacteria}

Six active sludge samples were obtained from three wastewater treatment plants. All samples were transported to the laboratory and screened to obtain the dye decolorizing organisms. All bacterial isolations were cultivated on mineral salts basic medium with the following composition (g/l): $\mathrm{Na}_{2} \mathrm{HPO}_{4}, 2.13 ; \mathrm{KH}_{2} \mathrm{PO}_{4}, 1.3 ; \mathrm{NH}_{4} \mathrm{Cl}, 0.5$; $\mathrm{MgSO}_{4}, 0.2 ; 1 \mathrm{~L}$ tap water and $1 \mathrm{ml}$ trace element solution per liter. The trace element solution had the following composition (g/l): $\mathrm{MgSO}_{4} \cdot 7 \mathrm{H}_{2} \mathrm{O}, 7.12 ; \mathrm{ZnSO}_{4} \cdot 7 \mathrm{H}_{2} \mathrm{O}$,
0.044; $\mathrm{MnSO}_{4} \cdot 4 \mathrm{H}_{2} \mathrm{O}, \quad 0.081 ; \mathrm{CuSO}_{4} \cdot 5 \mathrm{H}_{2} \mathrm{O}, \quad 0.0782$; $\mathrm{Na}_{2} \mathrm{MoO}_{4} \cdot 2 \mathrm{H}_{2} \mathrm{O}, 0.025 ; \mathrm{FeSO}_{4} \cdot 7 \mathrm{H}_{2} \mathrm{O}, 0.498$; Boric acid $0.1+0.27 \mathrm{ml}$ of $\mathrm{H}_{2} \mathrm{SO}_{4}$. The final $\mathrm{PH}$ was adjusted at 7.0. The mineral salts medium was supplemented with $1(\mathrm{~g} / \mathrm{l})$ yeast extract. The activated sludge samples $(2.5 \mathrm{ml})$ were transferred into $250 \mathrm{ml}$ flasks containing $50 \mathrm{ml}$ mineral salts medium and dye (prepared using a mixture of 9 types of dyes). All dyes ware mixed together to get stock solution of mixture of dyes $0.9(\mathrm{~g} / \mathrm{l})(0.1 \mathrm{~g} / \mathrm{l}$ of each dye). The stock solution was supplemented with a basic salt medium to get a final concentration of 0.1 (g/l). Each flask contained $50 \mathrm{ml}$ of a sterile mineral salts liquid medium mixed with azo dyes mixture dispensed with one gram of yeast extract. Each flask was inoculated with $2.5 \mathrm{ml}$ of activated sludge. All were incubated in a rotary incubator at $150 \mathrm{rpm}$ for 24 hours at $30^{\circ} \mathrm{C}$. Similar flasks were prepared and inoculated with $1 \mathrm{ml}$ of the content of the flasks of the first group. These were incubated for 24 hours. This step was repeated three times in a period of 72 hours. The last (third) group of flasks was incubated for five days. These flasks were used to isolate the target microorganisms by streaking a mineral salts agar medium containing the same ingredients of the previous broth medium, plus agar and $100 \mathrm{ppm}$ of an azo dyes mixture. Separate colonies of the predominant types of microorganisms were purified by re-streaking on the same medium. The purified isolates were examined microscopically to check for purity. Obtained pure cultures were maintained on nutrient agar at $4^{\circ} \mathrm{C}$ (in refrigerator) [11-13]. Ten morphologically different isolates were obtained from the previous step and studied for colony morphology.

\subsection{Screening Program (Testes) to Select the Most Potent Organisms}

First screening was done to test the ability of the purified isolates to utilize different groups of dyes as the sole carbon source. Screening to test the ability of isolated organisms to utilize direct blue 75 , direct blue 71 , reactive blue 194 and direct red 89 as the sole carbon source was carried out in a mineral salts basic medium used in isolation. Yeast extract was replaced by $0.1 \mathrm{~g} / 1$ individual dye. Organisms were selected on the basis of their ability to grow and reduce pigmentation under these conditions. Colonies of an over night growth were suspended in normal saline to obtain the optical density of 0.6 at wavelength $610 \mathrm{~nm}$. One milliliter of cell suspension was used to inoculate $100 \mathrm{ml}$ bottles containing $25 \mathrm{ml}$ mineral salts basic medium supplemented with $0.1 \mathrm{~g} / 1$ individual dye. Bottles were then incubated for seven days at $30^{\circ} \mathrm{C}$. A second screening was performed to ensure the ability of selected isolations to utilize different groups of dyes as the 
sole carbon source.

\subsection{Identification of the Most Potent of Azo Dyes-Decolorizing Bacterial Isolates}

The two most potent bacterial isolations (TN1 \& TN5) having the highest decolorization potentiality were selected to complete the study. They were identified on the basis of cell shape, cell arrangement, relation to oxygen, nutritional characteristics, physiological, and biochemical characteristics in terms of Comamanas acidovorns and Burkholdera cepace.

\subsection{Analytical Methods}

\subsubsection{Decolorization Assay}

All samples $(2 \mathrm{ml})$ were centrifuged at $11,000 \mathrm{rpm}$ for 10 min. The supernatant was read at absorbance with maximum ( $\lambda \max$ ) values using thermo spectronic-Genesys 20 spectrophotometer. The efficiency of color removal was expressed as the percentage of the decolorized dye concentration to that of the initial one, i.e., the difference between the initial dye concentration, Dye(i), and the residual dye concentration, Dye(r), of the sample:

$$
\text { Color removal }(\%)=\frac{\text { Dye }(\mathrm{i})-\text { Dye }(\mathrm{r})}{\text { Dye }(\mathrm{i})}
$$

\subsubsection{Determination of Total Protein}

The total protein determination was made according to the method used by Lowry [14] utilizing serum albumin as a standard protein.

\subsubsection{Determination of Biochemical Oxygen Demand (BOD)}

BOD determination was made according to the standard methods for examination of water and waste water $\left(20^{\text {th }}\right.$ edition).

\subsubsection{Determination of Chemical Oxygen Demand (COD)}

COD determination was made according to a closed reflux, colorimetric method standard method for examination of water and waste water $\left(20^{\text {th }}\right.$ edition).

\subsubsection{UV-Visible, Infra Red and HPLC Analysis}

Metabolites produced during biodegradation of acid orange 7 , direct blue 75 , and their mixture were extracted with equal volumes of ethyl acetate. The extract was dried over anhydrous $\mathrm{Na}_{2} \mathrm{SO}_{4}$ and evaporated in a rotary evaporator, and then dissolved in ethanol to use for all analyses [15]. The decolorization was monitored using UV-vis spectroscopy analysis (Hitachi U 2800). The active groups of degradation metabolites were monitored by using FT-IR spectroscopy analysis (Jasco, FT-IR 460 PLUS-Japan). HPLC analysis was carried out on a Ceccil model Adept CE 4900 chromatograph equipped with a Cecil model CE 4200 UV detector, an oven column model CE 4601, and a lichrosorb C18 column with a $4.6 \mathrm{~mm}$ internal diameter and $25 \mathrm{~cm}$ height. A mobile phase composed of $50 \%$ methanol, $0.3 \% \mathrm{H}_{3} \mathrm{PO}_{4}$, and $49.7 \%$ water was used at a flow rate of $0.5 \mathrm{ml} \cdot \mathrm{min}^{-1}$. Elutes were monitored by the UV absorption at $300 \mathrm{~nm}$ [16]. In all cases, the parent azo dyes acid orange 7 and direct blue 75 were used as a control.

\subsection{Optimization of Decolorization Ability for the Selected Isolates}

\section{Addition of Yeast Extract}

One $\mathrm{g} / \mathrm{L}$ yeast extract was supplemented to the mineral salt medium used in screening experiments in a trail to support growth and increase the degradation ability of the selected bacterial isolations. The experiment proceeded in triplicates at $\mathrm{pH} 7$ and an incubation temperature of $30^{\circ} \mathrm{C}$ in bottles containing $25 \mathrm{ml}$ medium solution.

\subsection{Decolorization under Different Culture Conditions}

The effect of various culture conditions such as ${ }_{\mathrm{p}} \mathrm{H}$, temperature, inoculum size, and incubation period on decolorization of acid orange 7 and direct blue 75 by Com. acidovorns-TN1 and Bur. Cepacia-TN5 was examined.

\subsubsection{Effect of PH on the Decolorization of Azo Dyes Acid Orange 7 and Direct Blue 75 by Com. Acidovorns-TN1 and Bur. Cepace-TN5}

Colonies of an overnight growth were suspended in normal saline solution to obtain optical density of $0.6 \mathrm{~g} / \mathrm{l}$ at $610 \mathrm{~nm}$ wavelength. One milliliter of cell suspension was used to inoculate $100 \mathrm{ml}$ bottles containing a $25 \mathrm{ml} \mathrm{min}$ eral salt basic medium, supplemented with $0.1 \mathrm{~g} / 1$ individual dye, and $1 \mathrm{~g} / 1$ yeast extract. The medium was adjusted to $\mathrm{pH}$ of 4, 6, 7, 8 and 9 using $(1 \mathrm{~N})$ hydrochloric acid $(\mathrm{HCl})$ and $(1 \mathrm{~N})$ sodium hydroxide $(\mathrm{NaOH})$. Bottles were incubated for seven days at $30^{\circ} \mathrm{C}$.

\subsubsection{Effect of Different Incubation Temperature on the Decolorization of Azo Dyes Acid Orange 7 and Direct Blue 75 by Com. Acidovorns TN1 and Bur. Cepace TN5}

The experiment was carried out in $100 \mathrm{ml}$ bottles containing $25 \mathrm{ml}$ mineral salt basic medium supplemented with $0.1 \mathrm{~g} / 1$ individual dye and $1 \mathrm{~g} / 1$ yeast extract. The medium was adjusted to $\mathrm{pH} 8$ and each bottle was inoculated with a predetermined equal cell density for the two strains. Bottles were divided to be incubated at different temperature: $10^{\circ} \mathrm{C}, 25^{\circ} \mathrm{C}, 30^{\circ} \mathrm{C}, 35^{\circ} \mathrm{C}$ and $40^{\circ} \mathrm{C}$. 


\subsubsection{Effect of Different Incubation Periods on the Decolorization of Azo Dyes Acid Orange 7 and Direct Blue 75 by Com. Acidovorns-TN1 and Bur. Cepace-TN5}

This experiment was carried out in order to investigate the effect of different incubation periods on the decolorization process of the two azo dyes by Com. acidovorns-TN1 and Bur. cepace-TN5. The two strains were allowed to grow in the two azo dyes under the optimum conditions determined from the previous experiments, and were then incubated for $6,12,24,48,72,120$ and 168 hours, respectively. At the end of each incubation period, azo dyes decolorization (\%) and the protein content were assayed.

\subsubsection{Effect of Different Inoculum Sizes on the Decolorization of Azo Dyes, Acid Orange 7 and Direct Blue 75, by Com. Acidovorns-TN1 and Bur. Cepace-TN5}

Different inoculation sizes of heavy cell suspension of the two bacterial isolates Com. acidovorns-TN1 and Bur. cepace-TN5 (prepared by washing each slant with $20 \mathrm{ml}$ of sterile saline solution under aseptic conditions and optical density was adjusted to obtain an optical density of 0.6 at $610 \mathrm{~nm}$ wavelength) were used. The following inocula sizes were applied via 0.2, 0.5, 1, 2 and $3 \mathrm{ml}$ per flask. All other optimal culture conditions were taken into consideration. At the end of incubation period the azo dyes biodegradation were determined for each flask as previously mentioned.

\subsubsection{Effect of Different Carbon Sources on the Decolorization of Azo Dyes Acid Orange 7 and Direct Blue 75 by Com. Acidovorns-TN1 and Bur. Cepace-TN5}

Different carbon sources were introduced into the two azo dyes mineral salts media at an equimolecular level located at $0.5 \mathrm{~g} / \mathrm{l}$. A parallel experiment was made without sugar as a control. The carbon sources were represented by sucrose, glucose, maltose, starch, dextrin, fructose, manitole and lactose. In all cases, other previously mentioned optimal conditions were taken into consideration.

\subsubsection{Effect of Different Nitrogen Sources on the Decolorization of Azo Dyes Acid Orange 7 and Direct Blue 75 by Com. Acidovorns-TN1 and Bur. Cepace-TN5}

Biodegradation of mineral salts media were supplemented with different nitrogen sources with equivalent amounts of nitrogen present in $0.5 \mathrm{~g} / \mathrm{l} \mathrm{NH} \mathrm{N}_{4} \mathrm{Cl}$. The particular nitrogen sources were $\mathrm{KNO}_{3}, \mathrm{NaNO}_{3}, \mathrm{NH}_{4} \mathrm{Cl}, \mathrm{NH}_{4} \mathrm{NO}_{3}$, $\left(\mathrm{NH}_{4}\right)_{2} \mathrm{NO}_{3}, A m m . \mathrm{SO}_{4}$, Amm.oxalate, Amm. Molybdenate, and peptone. All other optimal factors were carried out as previously mentioned. The azo dyes biodegradation were assayed for each separate nitrogen source as previ- ously mentioned.

\subsubsection{Effect of different Yeast Extract Concentrations on the Decolorization of Azo Dyes Acid Orange 7 and Direct Blue 75 by Com. acidovorns-TN1 and Bur. Cepace-TN5}

This test was performed to investigate the effect of different concentrations of yeast extract on the azo dyes biodegradation by Com. acidovorns-TN1 and Bur. cepaceTN5. This experiment was carried out by applying different concentrations of yeast extract $(0.1,0.25,0.5,1$ and $2 \mathrm{~g} / \mathrm{l})$. All concentrations were proceeded as previously mentioned optimal conditions.

\subsubsection{Effect of Different Incubation Types (Oxygen Concentrations) on the Decolorization of Azo Dyes Acid Orange 7 and Direct Blue 75 by Com. Acidovorns-TN1 and Bur. Cepacia-TN5}

This experiment was carried out in order to investigate the effect of incubation conditions on the biodegradation of azo dyes acid orange 7 and direct blue 75 by Com. Acidovorns-TN1 and Bur. cepace-TN5. This was carried out by incubating the flasks containing the mineral salts media with each azo dye in addition to the optimal sources of carbon and nitrogen resulting from the previous optimization in four ways: static incubation, shaking incubation at $150 \mathrm{rpm}$, anaerobic and aerobic-anaerobic incubation. At the end of incubation period, azo dyes decolorization were assayed as previously mentioned.

\subsubsection{Effect of Consortium as Com. Acidovorns-TN1 + Bur. Cepace.-TN5 on the Decolorization of Azo Dyes Acid Orange 7 and Direct Blue 75}

This experiment was carried out in order to investigate the effect of a consortium of Com. acidovorns-TN1 + Bur. cepace-TN5 on enhancing biodegradation of azo dyes acid orange 7 and direct blue 75 . This was carried out by inoculation of the two strains, Com. acidovorns-TN1 and Bur. cepace-TN5, into biodegradation media and incubation under all the optimal nutritional and environmental conditions. At the end of incubation period, the two azo dyes biodegradation was assayed as previously mentioned.

\section{Results}

\subsection{Isolation, Purification, and Screening Test for Azo Dye Decolorizing Bacteria}

Ten bacterial isolations were conducted from an aeration tank and the input effluent of three wastewater treatment plants (Eldwakhlia-Bassiun), as shown in Table 1.

Experiments on growth and the dye removal ability of the pure isolations growing in a mineral salts agar 
Table 1. Code numbers, isolates locality, cell morphology and gram, catalase reaction of the ten bacterial isolates used for azo dye biodegradation process.

\begin{tabular}{|c|c|c|c|c|c|c|}
\hline No & Code & Isolation locality & Cell morphology & $\begin{array}{c}\text { Gram } \\
\text { reaction }\end{array}$ & $\underset{\text { reaction }}{\mathrm{KOH}}$ & $\begin{array}{l}\text { Catalase } \\
\text { reaction }\end{array}$ \\
\hline 1 & TN1 & Aeration tank of Eldwakhliah WWTP & Rods & - & + & + \\
\hline 2 & MKD3 & Industrial input effluent of Eldwakhliah WWTP & Cocci & - & + & + \\
\hline 3 & MKD5 & Industrial input effluent of Eldwakhliah WWTP & Rods & - & + & \pm \\
\hline 4 & MKD7 & Industrial input effluent of Eldwakhliah WWTP & Rods & - & + & + \\
\hline 5 & TN5 & Aeration tank of Eldwakhliah WWTP & Rods & - & + & + \\
\hline 6 & MM5 & Aeration tank of Mahalet marhome WWTP & Rods & - & + & + \\
\hline 7 & MM7 & Aeration tank of Mahalet marhome WWTP & Rods & - & + & + \\
\hline 8 & $\mathrm{BO} 3$ & Aeration tank of bassuon WWTP & Rods & - & + & + \\
\hline 9 & TM7 & Aeration tank of Eldwakhliah WWTP & Rods & - & + & + \\
\hline 10 & $\mathrm{BO} 4$ & Aeration tank of bassuon WWTP & Rods & - & + & + \\
\hline
\end{tabular}

medium containing $100 \mathrm{ppm}$ dye revealed that TN1 \& TM2 grew rapidly with more visible colonies than others. Ten bacterial isolations were tested for their ability to utilize direct blue 75 , direct blue 71 , reactive blue 194 , and direct red 89 as the sole carbon source in the mineral salts basal medium used for isolation. Data presented graphically in Figure 1 shows the different capabilities of the ten bacterial isolations pertaining to this study. This effect can clearly be detected by reviewing the protein content values and their relationship to the decolorization percentage concerning different dyes.

Concerning the second survey, data revealed that direct red 89 and direct blue 75 gave the most promising results among all the four azo dyes under investigation. It is worthwhile to mention that reactive blue 194 failed to fulfill carbon source requirement for all ten bacterial isolations. With regard to the ten purified bacterial isolations under investigation, six were recorded to have given the highest decolorization percentage and protein content. The six bacterial isolates (TN1, MKD7, TN5, BO3, TM7 and BO4) were tested to grow in the same medium containing higher concentrations (500 ppm).

In the second screening, values of the decolorization percentage and protein content were generally decreased, and the best results were attained in the case of TN1\& TN5, so these compounds were selected to complete the study Figure 2.

In order to test the ability of TN1 \& TN5 to deal with wide range of azo dyes, the ability of the two compounds to utilize other members of azo dyes were tested. The new azo dyes were reactive red, mordant brown, acid yellow, acid orange 7 and acid black. Data presented graphically in Figure $\mathbf{3}$ showed that there was no great differences between decolorization percentage recorded after one day and that which was recorded after a period of seven days. Reactive red gave the highest degradation percentage and highest protein content by the two compounds.

After confirmatory screening experiments were performed, the mineral salts media was supplemented with 1 $\mathrm{g} / \mathrm{l}$ yeast extract to enhance the decolorization process.

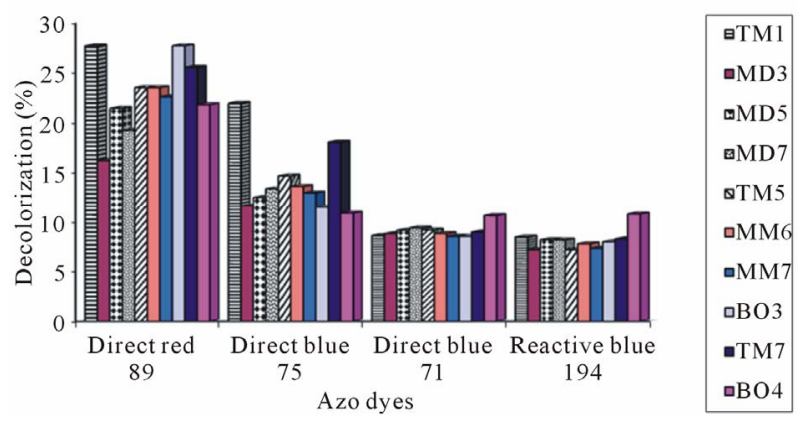

Figure 1. First Survey to test the ability of bacterial isolates to utilutilize azo dyes as sole carbon source.

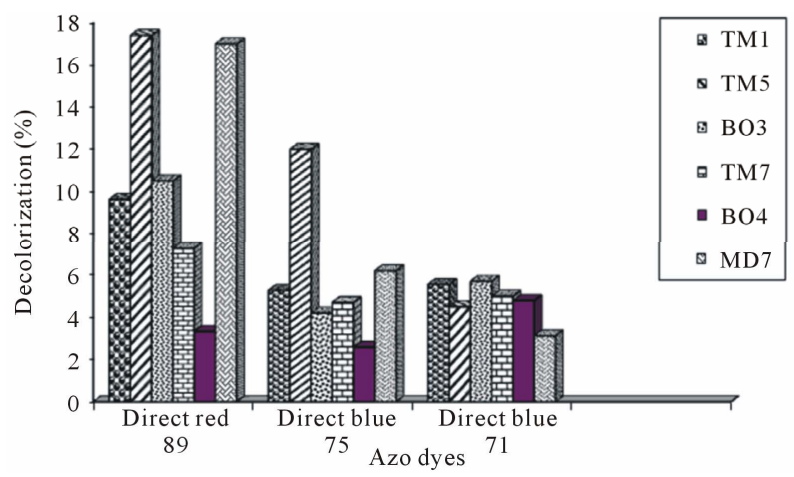

Figure 2. Second confirmatory Survey by the selected six isolates on the same azo dyes. 


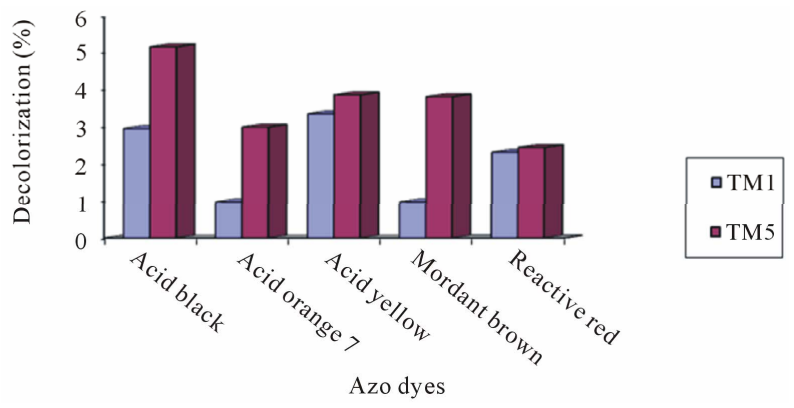

Figure 3. Ability determination of TN1 \& TN5 to deal with wide range of azo dyes.

The experiment proceeded to use seven azo dyes: Direct red 89, Direct blue 75, Acid orange 7, Acid yellow, acid black, Reactive red and Mordant brown. The decolorization percentage increased sharply with all dyes but the azo dyes. Direct blue 75 and Acid orange 7 showed the highest results, so they were selected to complete the study. The lowest results for the decolorization process were recorded for Mordant brown and Acid yellow. The lowest protein content was also recorded for compound TN1 in the decolorization of acid yellow and mordant brown. The results are presented graphically in Figure 4.

\subsection{Parameters Controlling Decolorization Process of Direct Blue 75 \& Acid Orange 7 by Com. Acidovorns-TN1 and Bur. Cepace-TN5}

Effect of Different Initial pH Values on the Decolorization of Acid Orange 7 and Direct Blue 75 after $24 h$ and $168 \mathrm{~h}$

$\mathrm{pH}$ value affects not only on the decolorization capability, but also on the color stability at $\mathrm{pH} 9$ after autoclaving. Color reduction occurred at $\mathrm{pH} 9$ after autoclaving in the case of both the dyes under study, but there was no effect with this particular $\mathrm{pH}$ on the color without autoclaving. The effect of different initial $\mathrm{pH}$ values (4 - 9) on decolorization of direct blue $75 \&$ acid orange 7 by Com. acidovorns-TN1 and Bur. cepace-TN5 was recorded after 24 hours and 168 hours, as presented graphically in Figures 5-7 The optimal $\mathrm{pH}$ for decolorization by both strains was $\mathrm{pH} 8$. The decolorization percentage was decreased when solution $\mathrm{pH}$ made more acidic. This seems to indicate that neutral and slightly basic $\mathrm{pH}$ values would be more favorable for the decolorization process of direct blue $75 \&$ acid orange 7 by Com. acidovornsTN1 and Bur. cepace-TN5. Results recorded for decolorization of acid orange 7 by Com. acidovorns-TN1 showed that the decolorization percentage decreased with the decrease in $\mathrm{pH}$ after 24 hours and 168 hours, and the optimum $\mathrm{pH}$ was 8 for this decrease. However, the optimum $\mathrm{pH}$ of growth was 7. On the other hand, results recorded for the decolorization of acid orange 7 by Bur.

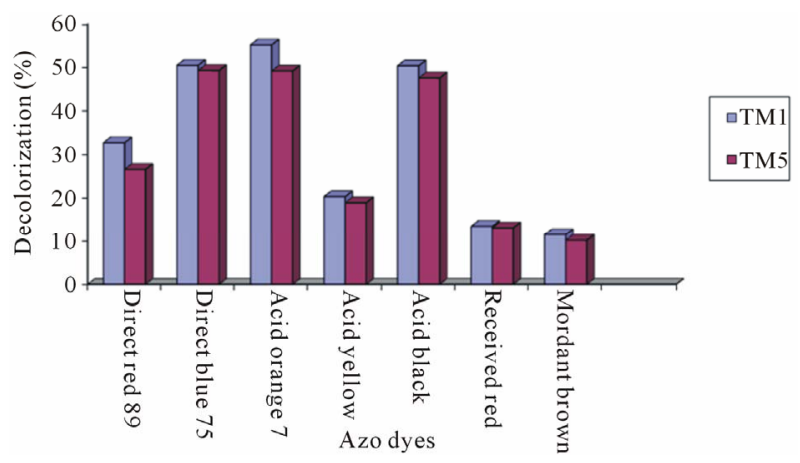

Figure 4. Decolorization of azo dyes by TN1 and TN5 in salts medium supplemented with yeast extract 1 (g/l).

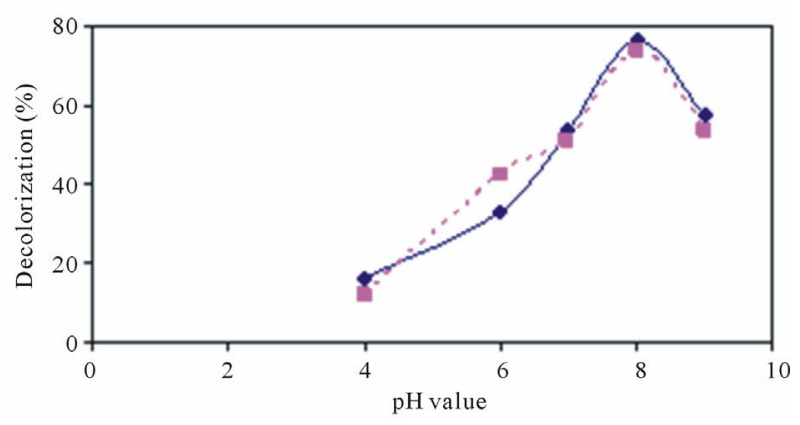

Figure 5. Effect of pH value on decolorization of acid orange 7 by Com. acidovorns-TN1 and Bur. cepace-TN5.

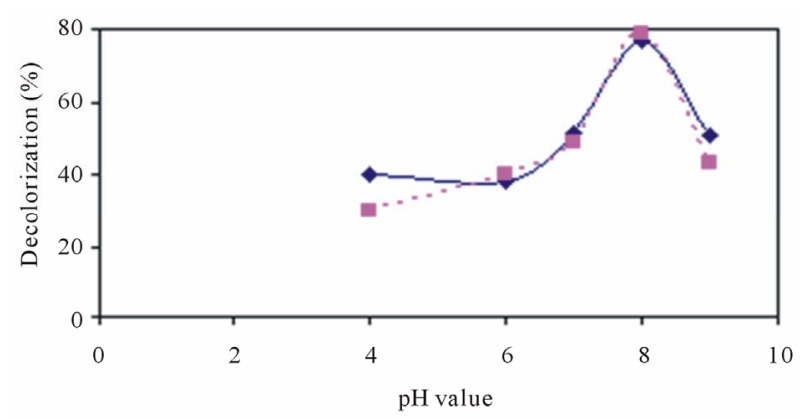

Figure 6. Effect of pH value on decolorization of acid orange 7 by Com. acidovorns-TN1 and Bur. cepace-TN5.

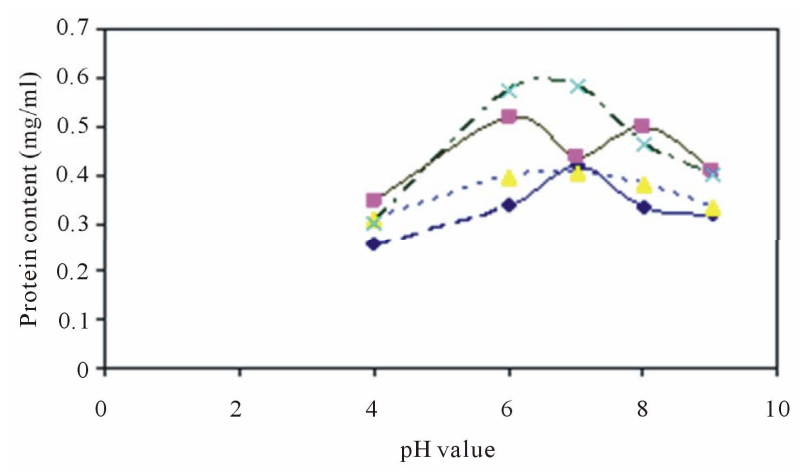

Figure 7. Effect of pH value on protein content of Com. acidovorns-TN1 and Bur. cepace-TN5 in decolorization process of acid orange 7 and direct blue 75 . 
cepace-TN5 also showed a decrease in the color removal percentage with $\mathrm{pH}$ decrease, but this decrease in color removal was not as sharp and optimum growth was at $\mathrm{pH}$ 8. The result recorded for decolorization of direct blue 75 by Com. acidovorns-TN1 showed that decolorization percentage decreased with a concurrent decrease in $\mathrm{pH}$ after 24 hours and 168 hours. The optimum $\mathrm{pH}$ was 8 , while the optimum $\mathrm{pH}$ of growth was 7 as in the decolorization of acid orange by the same strain. In contrast, decolorization of direct blue 75 by Bur. cepace-TN5 also showed a decrease in the color removal percentage, as the $\mathrm{pH}$ decreased, but this decrease in color removal was not nearly as sharp, and optimum growth was still at $\mathrm{pH}$ 8 as in the decolorization process in the case of acid orange by the same strain.

\subsection{Effect of Different Incubation Temperatures on the Decolorization Process after 24 Hours and 168 Hours}

The experiments were performed at different temperatures ranging from $10^{\circ} \mathrm{C}-40^{\circ} \mathrm{C}$. The decolorization increased as the temperature increased as evidenced in Figures 8-10. But the color removal ability of both strains decreased sharply at a temperature of $40^{\circ} \mathrm{C}$, and further increases in temperature resulted only in marginal reductions in decolorization activity of the two bacterial strains. The optimal incubation temperature for the decolorization process by the two strains was $35^{\circ} \mathrm{C}$. Decolorization percentage decreased as temperature dropped below $35^{\circ} \mathrm{C}$ or increased over this particular value. The growth of the two strains (protein content) also followed the same behavior of decolorization, so the optimum growth temperature of the two strains was determined to be $35^{\circ} \mathrm{C}$. There was no great difference between the decolorization of acid orange 7 by Com. acidovorns-TN1 at temperatures $30^{\circ} \mathrm{C}$ and $35^{\circ} \mathrm{C}$. Decolorization of direct blue 75 at temperature $10^{\circ} \mathrm{C}$ and $40^{\circ} \mathrm{C}$ was nearly the same for Com. acidovorns-TM and Bur. cepace-TN5. The result recorded for decolorization of acid orange by Com. acidovorns-TN1 or Bur. cepace-TN5 showed that the color removal at temperature $10^{\circ} \mathrm{C}$ was duplicated at $40^{\circ} \mathrm{C}$ after 24 hours and 168 hours.

\subsection{Effect of Different Incubation Periods on the Decolorization of Acid Orange 7 \& Direct Blue 75 by Com. Acidovorns-TN1 and Bur. Cepace-TN5}

Decolorization of AO $7 \&$ direct blue 75 by both bacterial strains was recorded at different intervals of time under optimum $\mathrm{pH}(\mathrm{pH} 8)$ and optimum temperature $\left(35^{\circ} \mathrm{C}\right)$ conditions, as shown in Figures 11-13. The results recorded for decolorization of acid orange 7 by Com. Acidovorns-TN1 showed that there were slight changes in

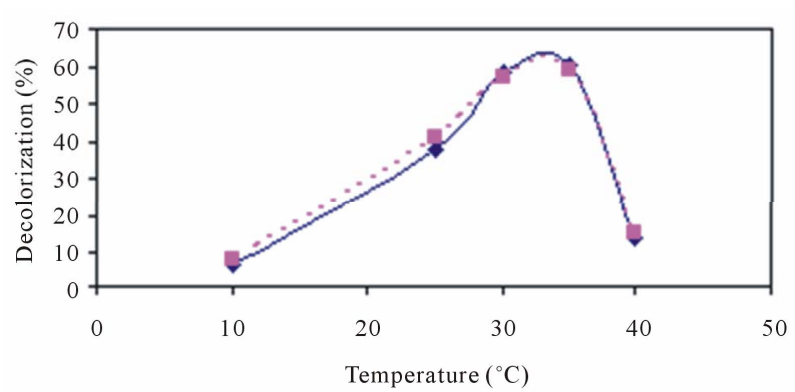

Figure 8. Effect of incubation temperature on decolorization process of acid orange 7 by Com. acidovorns-TN1 and Bur. cepace-TN5.

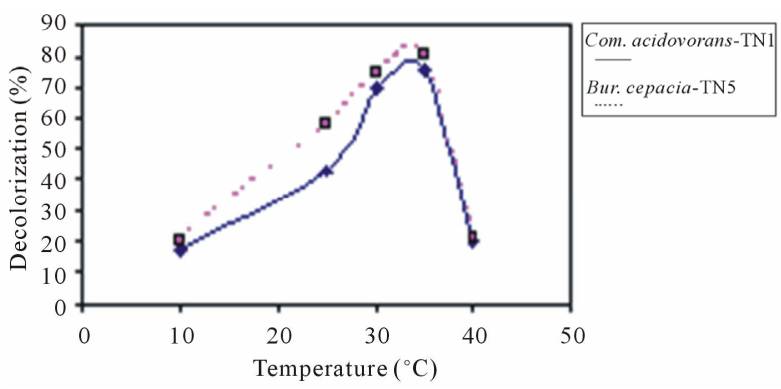

Figure 9. Effect of incubation temperature on decolorization process of direct blue 75 by Com. acidovorns-TN1 and Bur. cepace-TN5.

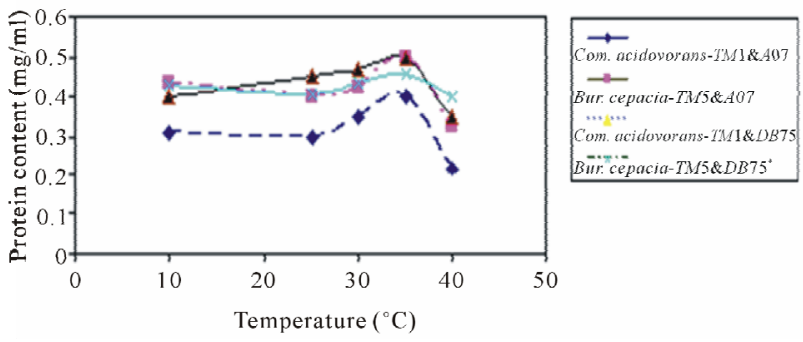

Figure 10. Relation between protein content and incubation temperature in decolorization process of acid orange $7 \&$ direct blue 75 by Com. acidovorns-TN1 and Bur. cepaceTN5.

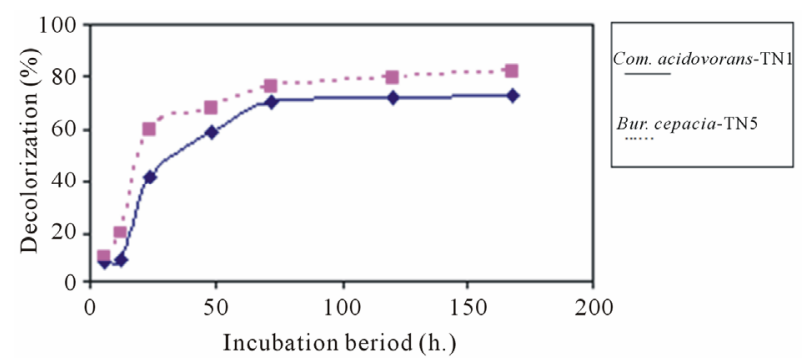

Figure 11. Effect of incubation period on decolorization process ofcid orange 7 by Com. acidovorns-TN1 and Bur. cepace-TN5.

color removal after six hours and 12 hours of incubation, but at 24 hours the decolorization percentage increased 


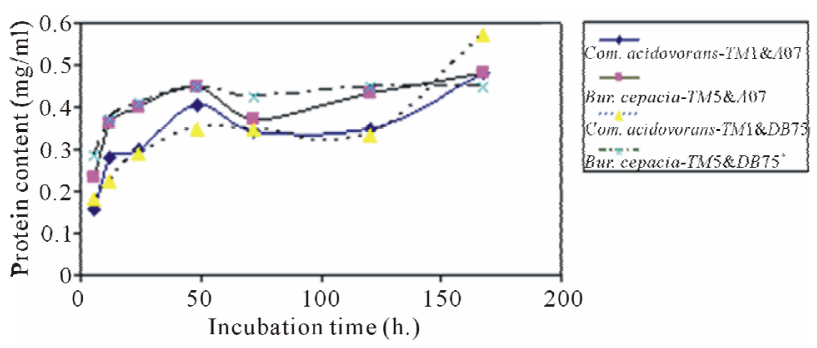

Figure 12. Effect of incubation period on decolorization process of Direct blue 75 by Com. acidovorns-TN1 and Bur. cepace-TN5.

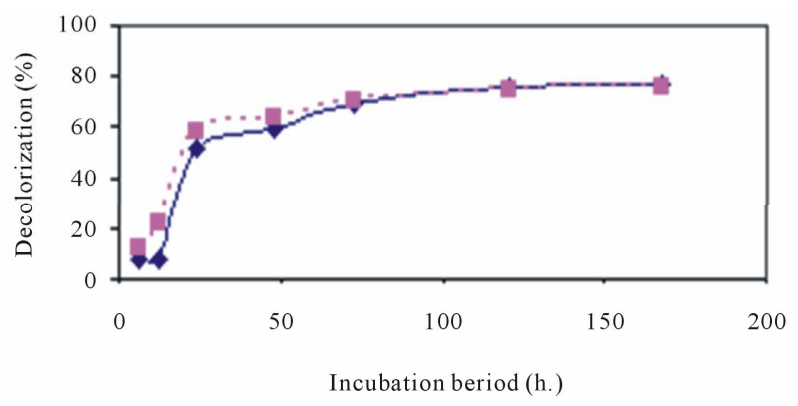

Figure 13. Relation between protein content and incubation period in decolorization process of acid orange $7 \&$ direct blue 75 by Com. acidovorns-TN1 and Bur. cepace-TN5.

sharply to reach more than $60 \%$ of the total decolorization percentage at the end of incubation. The progress in color removal after 24 hours became slow and the difference between the results recorded at 120 hours and 168 hours was only $1.3 \%$ color removal. The growth represented by protein content increased gradually, and not steeply as in decolorization process. On the other hand, the decolorization percentage recorded by Bur. cepace-TN5 with acid orange 7 showed detectable changes in the color removal percentage after 6 hours and 12 hours when compared with the changes in color removal by Com. acidovorns-TN1 during the same interval of time. Protein content measured after 6 and 12 hours for Bur. cepace-TN5 also was higher than that achieved in the same intervals by Com. acidovorns-TN1.

\subsection{Effect of Different Inocula Sizes on the Decolorization Process of Acid Orange 7 \& Direct Blue 75 by Com. Acidovorns-TN1 and Bur. Cepace-TN5}

Results presented graphically in Figures 14-16 indicated that there was no clear relationship detected between the inoculum size and the decolorization percentage after 24 or 120 hours. For instance, the decolorization of acid orange 7 by Com. acidovorns-TN1 after 24 hours did not show detectable differences at inoculum sizes $1 \mathrm{ml}, 2 \mathrm{ml}$, and $3 \mathrm{ml}$ respectively, but decolorization percentage did decrease at inoculum size $0.2 \mathrm{ml}$ and $0.5 \mathrm{ml}$. The deco-

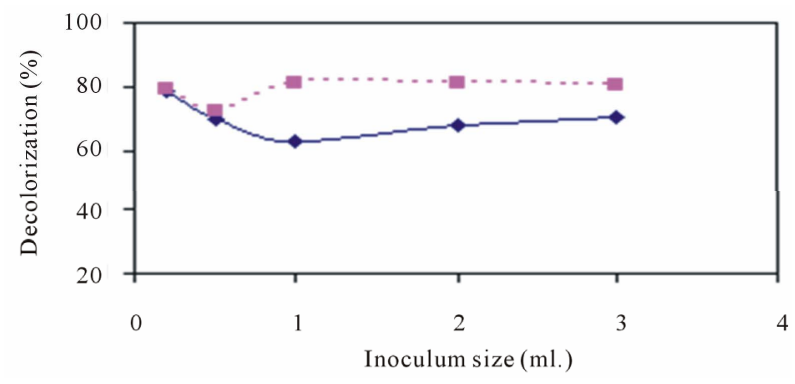

Figure 14. Effect of inoculum size on decolorization process of acid orange 7 by Com. acidovorns-TN1 and Bur. cepaceTN5.

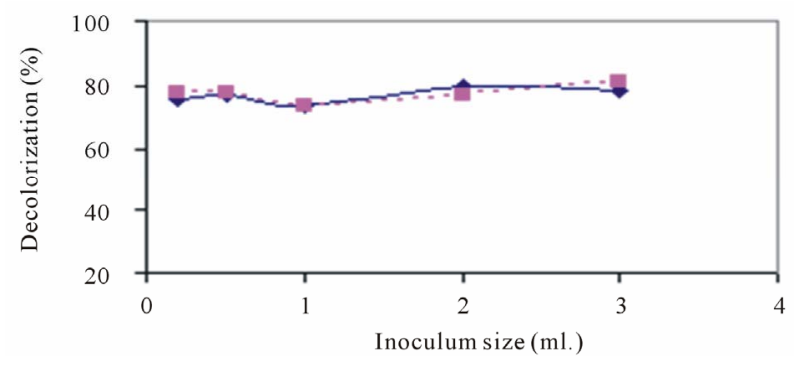

Figure 15. Effect of inoculum size on decolorization process of Direct blue 75 by Com. acidovorns-TN1and Bur. cepaceTN5.

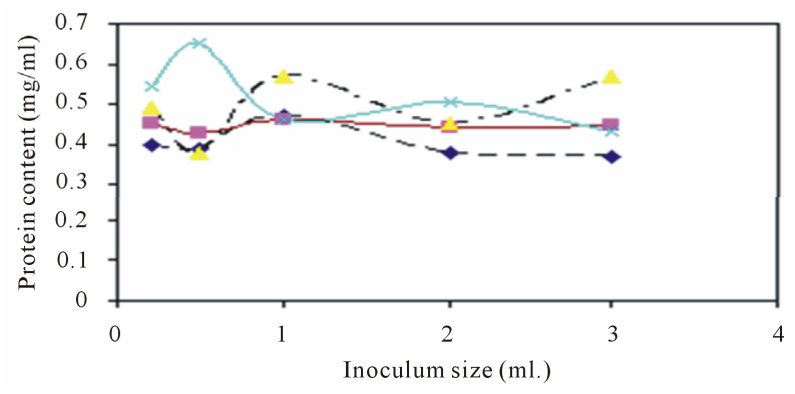

Figure 16. Relation between protein content and inoculum size in decolorization process of acid orange $7 \&$ direct blue 75 by Com. acidovorns-TN1 and Bur. cepace-TN5.

lorization at $0.2 \mathrm{ml}$ inoculum size was better than that at $0.5 \mathrm{ml}$, although the color removal achieved after 120 hours using $0.5 \mathrm{ml}$ inoculum size had the highest decolorization percentage recorded in this experiment. The decolorization of acid orange 7 by Bur. cepace-TN5 after 24 hours showed that the best decolorization percentage was at inoculum size $(2 \mathrm{ml})$ and the lowest value was for inoculum size $0.2 \mathrm{ml}$. Results recorded after 12 hours showed that inoculum size $3 \mathrm{ml}$ gave the highest color removal, and other inocula sizes gave nearly the same value of decolorization except for the inoculum size $1 \mathrm{ml}$, where the lowest value of decolorization percentage was recorded.

As discussed earlier, there was no clear relationship between the inoculum size and the decolorization per- 
centage after 24 hours or 120 hours. This condition was further proven by the result recorded for the decolorizetion of direct blue 75 by Com. acidovorns-TN1 and Bur. cepace-TN5.

Decolorization of direct blue 75 by Com.acidovorans$\mathrm{N} 1$ after 24 hours showed detectable differences at different inocula sizes. Decolorization using inoculum size 0.5 was optimal, followed by decolorization using inoculum size 0.2 . The lowest result was recorded for the inoculum size of $3 \mathrm{ml}$. But, decolorization of direct blue 75 by Com. acidovorns-TN1 after 120 hours indicated that the highest color removal was recorded at the $0.2 \mathrm{ml}$ inoculum size. The relationship between decolorization percentage and inoculum size was absent in the decolorization of direct blue 75 by Bur. cepace-TN5, where it was found that the best decolorization after 24 hours was a inoculum size of $2 \mathrm{ml}$, but the best result recorded after 120 hours was for the $1 \mathrm{ml}$ inoculum size. The recorded protein content for the decolorization of acid orange $7 \&$ direct blue 75 by Com. acidovorns-TM and Bur. Cepace-TN5 had the same behavior, so we are unable to establish a clear relationship between protein content and inoculum size or decolorization percent but in general. The values of protein content of the two strains at any inoculum size with direct blue 75 were higher than those of the two strains at any inoculum size with acid orange 7.

\subsection{Effect of Different Carbon Sources on the Decolorization of Acid Orange 7 \& Direct Blue 75 by Com. Acidovorns-TN1 and Bur. Cepace-TN5}

Textile industrial effluents deficient in carbon content and biodegradation without any extra carbon source is very difficult achieve. Therefore, different co-substrates such as sucrose, glucose, maltose, starch, dextrin, fructose, manitole and lactose $(0.5 \mathrm{~g} / 1)$, were supplemented in the medium and decolorization of all the two dyes (acid orange $7 \&$ direct blue 75 ) was studied individually by Com. acidovorns-TN1 and Bur. cepace-TN5. Results presented graphically in Figures $\mathbf{1 7}$ and $\mathbf{1 8}$ revealed that the decolorization of acid orange $7 \&$ direct blue 75 was clearly dependent on the presence of a carbon source. Results recorded for the decolorization of acid orange 7 by Com. acidovorns-TN1 showed that the best decolorization percentage was found to in presence of starch as the carbon source, followed by fructose then maltose. Dextrin and manitole recorded the lowest decolorization percentage. The highest protein content was achieved with glucose and fructose. The lowest protein content was recorded by adding manitole as the carbon source, which is the same as in the decolorization process. Decolorization of acid orange 7 by Bur. cepace-TN5 showed

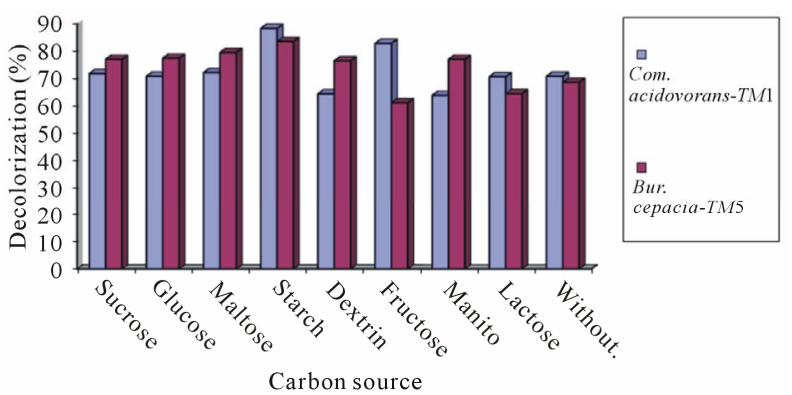

Figure 17. Effect of different carbon sources on decolorization of acid orange by Com. acidovorns-TN1 and Bur. cepace-TN5.

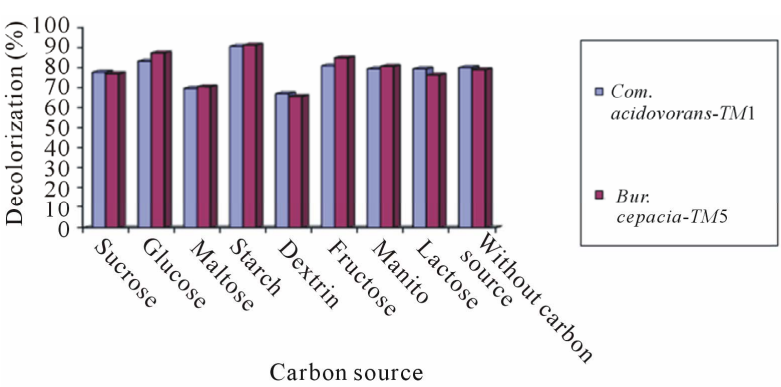

Figure 18. Effect of different carbon source on decolorization of direct blue 75 by Com. acidovorns-TN1 and Bur. cepace-TN5.

that the best decolorization percentage was recorded in the presence of starch as a carbon source, followed by maltose, then glucose. Fructose and lactose recorded the lowest decolorization percentage. The highest protein content was achieved with glucose and fructose as in the decolorization of the same dye by Com. acidovorns-TN1. The lowest protein content was recorded when manitole was used as the carbon source in decolorization process. Starch was also the best co-substrate by using a carbon source in the decolorization of direct blue 75 by Com. acidovorns-TN1 \& Bur. cepace-TN5, followed by glucose and then fructose in the case of decolorization by Com. acidovorns-TN1, and glucose followed by fructose in case of decolorization by Bur. cepace-TN5. The highest protein content was achieved with fructose and dextrin in case decolorization by Com. acidovorns-TN1, and fructose then maltose in case of decolorization by Bur. cepace-TN5. The lowest protein content was by adding sucrose as a carbon source in decolorization of direct blue 75 by each of the two strains respectively.

\subsection{Effect of Different Nitrogen Sources on the Decolorization of Acid Orange 7 \& Direct Blue 75 by Com. Acidovorns-TN1 and Bur.Cepacia-TN5}

A number of organic and inorganic sources of nitrogen were used in this experiment. Results presented graphically in Figures 19 and $\mathbf{2 0}$ indicate that, peptone gave the 
best decolorization percentage and the highest protein content in the decolorization of direct blue 75 or acid orange 7 by each of the two strains respectively. Ammonium oxalate was the next best in the decolorization of each of both dyes by both strains, except in case of decolorization of direct blue 75. Com. acidovorns-TN1 and amm.molebdate were nearly equivalent in color removal ability in the decolorization of direct blue 75 by Com. acidovorns-TN1. The lowest color removal was attained by using $\left(\mathrm{NH}_{4}\right)_{2} \mathrm{HPO}_{4}$ as the nitrogen source in the decolorization of acid orange 7 by each of the two strains individually. The lowest color removal in the case of direct blue 75 was attained by adding potassium nitrate in the decolorization by both of the two strains individually.

We can summarize the optimum condition resulting from the previous experiments as follows in Table 2.

\section{Discussion}

Textile dyeing industries is one of the fastest growing fields and a major export oriented industrial sector, especially in El-Mahalla Elkobra. Azo dye production ac-

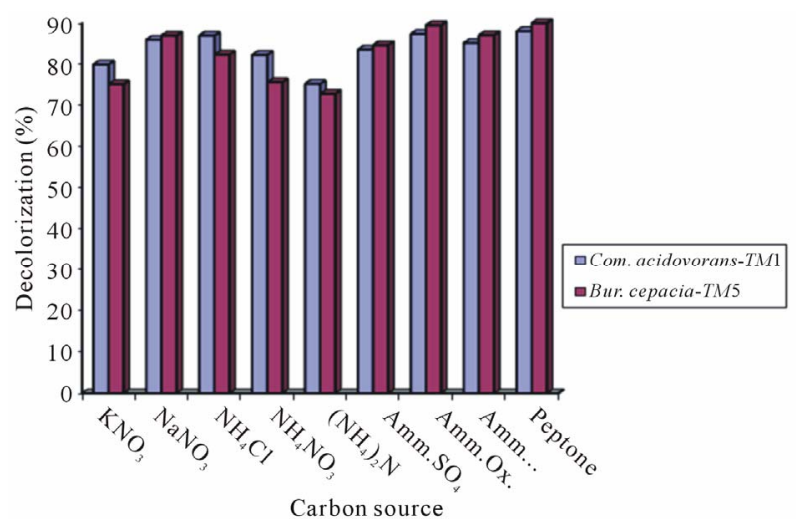

Figure 19. Effect of different nitrogen ources on decolorizetion of acid orange by Com. acidovorns-TN1 and Bur. Cepace-TN5.

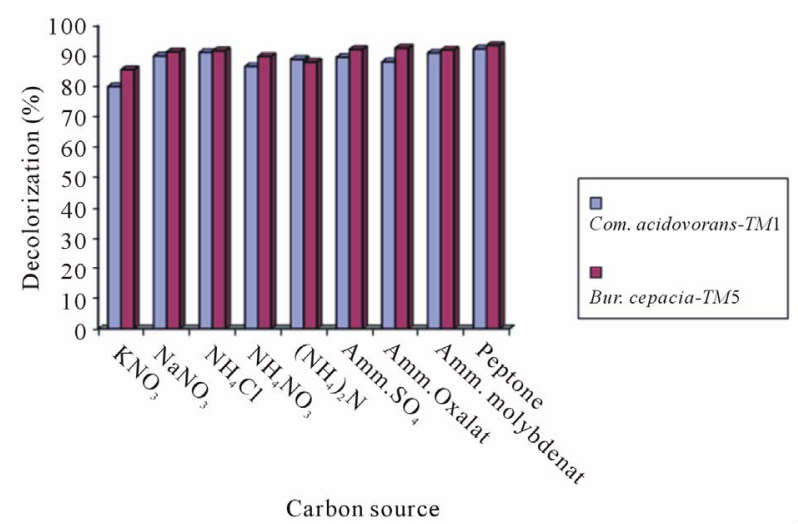

Figure 20. Effect of different nitrogen sources on decolorization of direct blue 75 by Com. acidovorns-TN1 and Bur. Cepace-TN5.
Table 2. A summery for the best conditions resulted from the study for decolorization of acid orange 7 and direct blue 75 by Com. acidovorns-TN1 \& Bur. cepace-TN5.

\begin{tabular}{ccc}
\hline Condition & Com. acidovorns TN1 & Bur. cepace TMS \\
\hline pH & 8 & 8 \\
Temperature & 35 & 35 \\
Incubation period & 120 hours & 120 hours \\
Carbon source & Starch & Starch \\
Nitrogen source & peptone & peptone \\
Incubation condition & Anaerobic & Anaerobic \\
\hline
\end{tabular}

counts for more than 1 million tons per year of the world industrial output, and during dying processes, about $40 \%$ of this huge amount of azo dyes ends up in drainage. In addition, about 40 - $65 \mathrm{~L}$ of textile effluent is generated per $\mathrm{kg}$ of cloth produced. On the other hand the release of these compounds into the environment presents serious health problems related to both aesthetic pollution and their toxicity [17]. Colored-dye-wastewater treatment and decolorization presents an arduous task. Wide ranges of $\mathrm{pH}$, salt concentrations and chemical structures often add to the complication. There are many reports on the use of physicochemical methods for color removal from dyes containing effluents [18]. Extensively used coagulation/flocculation techniques produce large amounts of sludge, which requires safe disposal. Partial absorption and membrane filtration techniques lead to secondary waste streams which need further treatment. These constraints have led to the adoption of advanced oxidation processes (AOP) and biological methods as attractive options for the treatment of dye-containing wastewaters. AOP is defined as those processes that use strong oxidizing agents $\left(\mathrm{H}_{2} \mathrm{O}_{2}\right.$, Fenton's reagent) or heterogenous photocatalysts, such as $\mathrm{TiO}_{2}, \mathrm{ZnO}_{2}, \mathrm{Mn}$, or $\mathrm{Fe}$ in the presence or absence of an irradiation source. These involve mainly the generation of $(\mathrm{OH})$ radicals for the destruction of refractory and hazardous pollutants [19]. These methods do not produce solid waste. However, both AOP and the membrane filtration methods are energy and cost intensive. Among the most economically viable choices available for effluent treatment/decolorization, and also the most practical in terms of manpower requirements and running expenses to adopt and develop, appear to be effect utilization of biological treatments. Fungal, bacterial and yeast decolorization are a promising alternative to replace or supplement present treatment processes. The main objective of the present work is an investigation of the isolation, purification, and screening of bacterial isolations to test whether they have the ability to decolorize and mineralize models of azo dyes, and optimize this ability for application in textile wastewater 
treatment.

In this regard, ten bacterial strains were isolated from different wastewater treatment plants, most of them exposed to drainage of colored textile effluents in addition to domestic effluents. These bacterial strains were selected after being grown at $30^{\circ} \mathrm{C}$ and $\mathrm{pH} 7$ in a mineral salt medium supplemented with yeast extract and a mixture of azo dyes at the rotary shaker for 24 hours. This step was repeated in order to permit the bacterial species to have the ability to survive in the presence of the dye.

A screening test for the ability of this isolates to utilize azo dyes as a sole carbon source was established to select the most potent organisms and exclude the chance that decolorization may have occurred due to adsorption alone. This technique was used by [16]. Where the ability of halophilic and halotolerant bacterial strains to utilize remazole blacke $\mathrm{B}$ as the sole carbon source was used to select the most effective strains. The screening was done in broth and solid mineral salt media containing different individual dyes to isolate effective organisms in the dyes used to complete this study. Screening tests were conducted three times on different groups of azo dyes to support the selection of organisms which have the ability to utilize different azo dyes as sole carbon sources.

This trial resulted in the fact that only two bacterial isolates TN1 and TN5 were considered to be the best decolorizers of most of the azo dyes used in screening.

The selected two bacterial strains were isolated from the Elmahalla Elkopra wastewater treatment plant, which is exposed to drainage from the textile industry, meaning that TN1 and TN5 were adapted bacterial strains. [20], by studying the textile effluent biodegradation potentialities of textile effluent-adapted and non adapted bacteria, found that there were no great differences in the decolorization ability between adapted and non adapted bacteria. In addition, plasmids were not detected in any of the strains from the effluent adapted or non-adapted sources.

All bacterial strain pellets retained its original color and was not deeply colored because of adsorbed dyes. This indicates that, color removal was due to degradation, and not only to adsorption [21]. The low protein content and low color removal percentage observed in screening tests were attributed to the fact that azo dyes are deficient in carbon content and biodegradation without any extra carbon sources being very difficult. So, optimization experiments were initiated by supplementing the menial salt medium containing dyes with yeast extract. The color removal percentage of most dyes increased sharply after the addition of yeast extract and this is in accordance with other reports [22]. Metabolism of yeast extract is considered essential for the regeneration of $\mathrm{NADH}$, which is the electron donor for the azo bond reduction [16]. The low decolorization percentage of azo dyes, Mordant Brawn, Reactive red and Acid yellow, may due to the fact that decolorization of azo dyes is affected by the permeability of the cell membrane depending upon the molecular weights and intramolecular hydrogen bonds between the azo and hydroxyl groups [23]. Since the two bacterial strains TN1 and TN5 were the most potent decolorizers of the azo dyes under study, they were selected purposely for their identification as well as optimization of their color removal ability of the two azo dyes, Acid orange 7 and Direct blue 75 . These colors were also selected to complete the study representing the other azo dyes because they gave the highest color removal ability in screening experiments, and therefore represent the most usable groups of azo dyes. Identification trials indicate that they are related to genus Comamonas and Burkholderia (previously seudomonas), therefore they can be both Com. acidovorns-TN1 and Bur. cepace-TN5. Although there is not sufficient research on using Comamonas sp. and Burkholderia sp. in the decolorization of textile wastewater containing azo dyes, the history of these two species in bioremediation, especially in the degradation of compounds related to unites which azo dyes are constructed (as nitro aromatics), indicate that the use of Comamonas $\mathrm{sp}$ and Burkholderia $\mathrm{sp}$ in this field is promising. Burkholderia sp. strain AK-5 utilized 4-aminophenol (this compound is an intermediate in the degradation of hydroxyacetanilide and azo dyes) as the sole carbon, nitrogen, and energy sources. A pathway for the metabolism of 4aminophenol in strain AK-5 was proposed based on the identification of three key metabolites by gas chromatography-mass spectrometry analysis. Strain AK-5 converted 4-aminophenol to 1,2,4-trihydroxybenzene via 1,4-benzenediol. 1,2,4 Trihydroxybenzene 1,2-dioxygenase cleaved the benzene ring of 1,2,4-trihydroxybenzene to form maleylacetic acid. The enzyme showed high dioxygenase activity only for 1,2,4-trihydroxybenzene, with $\mathrm{Km}$ and Vmax values of $9.6 \mathrm{M}$ and $6.8 \mathrm{~mol}$ min_1 mg of protein_1, respectively [24]. Also, Nitroaromatic, a compound widely used as dyes, was depredated by Burkholderia sp. For example, 4-Methyl-5nitrocatechol (4M5NC) monooxygenase (DntB) from Burkholderia sp. strain DNT catalyzes the second step of 2,4-dinitrotoluene degradation by converting 4M5NC to 2-hydroxy-5-methylquinone, with the concomitant removal of the nitro group.

Pseudomonas is classified as an extremely large, versatile and adaptable class of microorganisms, and it is not surprising that the Pseudomonas species have featured prominently in research involving the degradation of xenobiotic azo compounds. The biodegradation of azo dyes by Pseudomonas cepacia 13NA was investigated by using the dyes, CI Acid Orange 12, CI Acid Orange 20 and CI Acid Red 88. A three-stage continuous culture 
system (with the flasks arranged in a series) was found to be more successful then a one stage system, with respect to the rate of degradation of the dyes. This was attributed to: 1) An abundance of nutrients in the first stage of the cultivation system which resulted in a rapid increase in the bacterial population, increasing the number of potential azo degrading bacteria; and 2) A consequent paucity of nutrients in the second and third culture flasks which forced the microorganisms to assimilate the azo dyes into their growth, i.e. the azo dyes were degraded under nutrient limited conditions. These results are unusual as a pre-requisite for degradation of azo dyes is usually that a supplemental carbon source is provided to sustain the metabolic activity of the azo reducing microbial population [4].

\section{REFERENCES}

[1] C. M. Carliell, S. J. Barclay, N. Naidoo, C. A. Buckley, D. A. Mulholland and E. Senior, "Microbial Decolorization of a Reactive Azodye under Anaerobic Conditions," Water $S A$, Vol. 21, No. 1, 1995, pp. 61-69.

[2] N. Dafale, S. Watea, S. Meshram and T. Nandya, "Kinetic Study Approach of Remazol Black-Buse for the Development of Two-Stage Anoxic-Oxic Reactor for Decolorization/Biodegradation of Azo Dyes by Activated Bacterial Consortium," Journal of Hazardous Materials, Vol. 159, No. 2-3, 2008, pp. 319-328. doi:10.1016/i.jhazmat.2008.02.058

[3] A. M. Talarposhti, T. Donnelly and G. K. Anderson, "Colour Removal from a Simulated Dye Wastewater Using a Two Phase Anaerobic Packed Bed Reactor," Water Research, Vol. 35, No. 2, 2001, pp. 425-432. doi:10.1016/S0043-1354(00)00280-3

[4] K. Wuhrmann, K. L. Mechsner and T. H. Kappeler, "Investigation on Rate Determining Factors in the Microbial Reduction of Azo Dyes," Applied Microbiology and Biotechnology, Vol. 9, No. 4, 1980, pp. 325-338. doi:10.1007/BF00508109

[5] D. Deng, J. Guo, G. Zeng and G. Sun, "Decolorization of Anthraquinone, Triphenylmethane and Azo Dyes by a New Isolated Bacillus Cereus Strain DC11," International Biodeterioration \& Biodegradation, Vol. 62, No. 3, 2008, pp. 263-269.

[6] D. Brown and P. Laboureur, "The Degradation of Dyestuffs: Part I. Primary Biodegradation under Anaerobic Conditions," Chemosphere, Vol. 12, No. 3, 1983, pp. 397-404. doi:10.1016/0045-6535(83)90114-5

[7] E. Razo-Flores, M. Luijten, B. Donlon, G. Lettinga and J. Field, "Complete Biodegradation of the Azo Dye Azosalicylate under Anaerobic Conditions," Environmental Science and Technology, Vol. 31, No. 7, 1997, pp. 20982103. doi:10.1021/es960933o

[8] S. Chinwetkitvanich, M. Tuntoolvest and T. Panswad, "Anaerobic Decolorization of Reactive Dyebath Effluents by a Two Stage UASB System with Tapioca as Co- Substrate," Water Research, Vol. 34, No. 8, 2000, pp. 2223-

\section{2. doi:10.1016/S0043-1354(99)00403-0}

[9] W. G. Levine, "Metabolism of Azo Dyes: Implication for Detoxification and Activation," Drug Metabolism Review, Vol. 23, No. 3-4, 1991, pp. 253-309. doi:10.3109/03602539109029761

[10] F. He, W. R. Hu and Y. Z. Li, "Biodegradation Mechanisms and Kinetics of Azo Dye 4BS by a Microbial Consortium," Chemosphere, Vol. 57, No. 4, 2004, pp. 293 301. doi:10.1016/j.chemosphere.2004.06.036

[11] N. Hayase, K. Kouno and K. Ushio, "Isolation and Characterization of Aeromonas sp. B-5 Capable of Decolorizing Various Dyes," Journal of Bioscience and Bioengineering, Vol. 90, No. 5, 2000, pp. 570-573.

[12] K. Kumar, S. S. Devi, K. Krishnamurthi, S. Gampawar, N. Mishra, G. H. Pandya and T. Chakrabarti, "Decolorization, Biodegradation and Detoxification of Benzidine Based Azo Dyes," Bioresource Technology, Vol. 97, No. 3, 2006, pp. 407-413.

[13] B. Chen, "Understanding Decolorization Characteristic of Reactive Azo Dyes by Pseudomonas Luteola: Toxicity and Kinetics," Process Biochemistry, Vol. 38, No. 3, 2002, pp. 437-446. doi:10.1016/S0032-9592(02)00151-6

[14] O. H. Lowry, N. J. Rosebrough, L. A. Farr and R. J. Randall, "Protein Determination with the Folin Phenol Reagent," Journal of Biological Chemistry, Vol. 193, 1951, p. 265.

[15] D. C. Kalyani, A. A. Telke, R. S. Dhanve and J. P. Jadhav, "Ecofriendly Biodegradation and Detoxification of Reactive Red 2 Textile Dye by Newly Isolated Pseudomonas sp. SUK1," Journal of Hazardous Materials, Vol. 163, No. 2-3, 2009, pp. 735-742.

[16] S. Asad, M. A. Amoozegar, A. A. Ppurbabaee, M. N. Sarbolouki and S. M. M. Dastgheib, "Decolorization of Textile Azo Dyes by Newly Isolated Halophilic and Halotolerant Bacteria," Bioresource Technology, Vol. 98, No. 11, 2007, pp. 2082-2088. doi:10.1016/j.biortech.2006.08.020

[17] G. Mezohegyi, A. Kolodkin, U. I. Castro, C. Bengoa, F. Stuber, J. Font and A. Fabregat, "Effective Anaerobic Decolorization of Azo Dye Acid Orange 7 in Continuous Up Flow Packed-Bed Reactor Using Biological Activated Carbon System," Industrial \& Engineering Chemistry Research, Vol. 46, No. 21, 2007, pp. 6788-6792. doi:10.1021/ie0616920

[18] J. H. Churchley, "Removal of Dyewaste Color from Sewage effluent-The Use of a Full Scale Ozone Plant," $W a$ ter Science and Technology, Vol. 30, 1994, pp. 275-284.

[19] I. A. Alaton, I. A. Balcioglu and D. W. Bahnemann, “Advanced Oxidation of a Reactive Dye Bath Effluent: Comparison of $\mathrm{O}_{3}, \mathrm{H}_{2} \mathrm{O}_{2} / \mathrm{UV}-\mathrm{C}$ and $\mathrm{TiO}_{2} / \mathrm{UV}-\mathrm{A}$ Process," Water Research, Vol. 36, No. 5, 2002, pp. 1143-1154. doi:10.1016/S0043-1354(01)00335-9

[20] O. D. Olukanni, A. A. Osuntoki and G. O. Gbenle, "Textile Effluent Biodegradation Potentials of Textile Adapted and Non-Adapted Bacteria," African Journal of Iotechnology, Vol. 5, No. 20, 2006, pp. 1980-1984.

[21] K. C. Chen, W. T. Huang, J. Y. Wu and J. Y. Houng, "Microbial Decolorization of Azo Dyes by Proteus Mir- 
abilis," Journal of Industrial Microbiology \& Biotechnology, Vol. 23, No. 1, 1999, pp. 686-690.

doi:10.1038/sj.jim.2900689

[22] K. C. Chen, J. Y. Wu, D. J. Liou and S. J. Hwang, "Decolorization of Textile Dyes by Newly Isolated Bacterial Strains," Journal of Biotechnology, Vol. 101, No. 1, 2003, pp. 57-68. doi:10.1016/S0168-1656(02)00303-6

[23] C. Yatome, T. Ogawa, D. Koda and E. Ikeda, "Biodegradability of Azo and Triphenylmethane Dyes by Pseu- domonas Pseudomallei 13NA," Journal of the Society of Dyers and Colourists, Vol. 97, No. 4, 1981, pp. 166-169.

[24] S. Takenaka, S. Okugawa, M. Kadowaki, S. Murakami and K. Aoki1, "The Metabolic Pathway of 4-Aminophenol in Burkholderia sp. Strain AK-5 Differs from That of Aniline and Aniline with C-4 Substituents," Applied and Environmental Microbiology, Vol. 69, No. 9, 2003, pp. 5410-5413. doi:10.1128/AEM.69.9.5410-5413.2003 